\title{
ON THE EQUIVALENCE OF CLASSES OF FOURIER COEFFICIENTS
}

\section{LÁSZLÓ LEINDLER}

Abstract. It is shown that the classes of Fourier coefficients defined by Fomin, furthermore by C. V. Stanojevič and V. B. Stanojevič are identical.

Mathematics subject classification (1991): 26D15, 42A10.

Key words and phrases: Inequalities, cosine series, Fourier coefficients, embedding relations.

\section{REFERENCES}

[1] G. A. Fomin, A class of trigonometric series, Mat. Zametki 23 (1978), 213-222.

[2] J. W. GARRETT AND C. V. STANOJEVIČ, Necessary and sufficient conditions for $L^{1}$-convergence of trigonometric series, Proc. Amer. Math. Soc. 60 (1976), 68-71.

[3] C. V. STANOJEVIČ, Classes of $L^{1}$-convergence of Fourier and Fourier-Stieltjes series, Proc. Amer. Math. Soc. 82 (1981), 209-215.

[4] C. V. StanojeVič And V. B. Stanojevič, Generalizations of the Sidon-Telyakovskil̆ theorem, Proc. Amer. Math. Soc. 110 (1987), 679-684.

[5] S. A. TELYAKOVSKII, On a sufficient condition of Sidon for integrability of trigonometric series, Mat. Zametki 14 (1973), 317-328.

[6] Ž. Tomovski, A note on some classes of Fourier coefficients, Math. Ineq. \& Appl. (Zagreb) 2 (1999), $15-78$. 